\title{
Nanopores Structure in Electrospun Bacterial Cellulose
}

\author{
Ligia Maria Manzine Costa ${ }^{1}$, Gabriel Molina de Olyveira ${ }^{1 *}$, Pierre Basmaji ${ }^{2}$, Lauro Xavier Filho ${ }^{3}$ \\ ${ }^{1}$ Department of Nanoscience and Advanced Materials, Federal University of ABC, Santo André, Brazil; ${ }^{2}$ Innovatec's-Biotechno- \\ logy Research and Development, São Carlos, Brazil; ${ }^{3}$ Natural Products Laboratory and Biotechnology, UNIT, Aracaju, Brazil. \\ Email: "gmolyveira@yahoo.com.br
}

Received October $16^{\text {th }}, 2011$; revised November $14^{\text {th }}, 2011$; accepted December $4^{\text {th }}, 2011$

\begin{abstract}
Bacterial cellulose (BC) has established to be a remarkably versatile biomaterial and can be used in wide variety of applied scientific endeavours, especially for medical devices, lately, bacterial cellulose mats are used in the treatment of skin conditions such as burns and ulcers, because of the morphology of fibrous biopolymers serving as a support for cell proliferation, its pores allow gas exchange between the organism and the environment. Moreover, the nanostructure and morphological similarities with collagen make BC attractive for cell immobilization and cell support. In this work, we obtain first electrospun bacterial cellulose mats after chemical treatment and without conductive additives. With DMA/LiClmechanism dissolution, modified bacterial cellulose was easily electrospun in chloroform/acetone solvents in comparison with BC unmodified. FTIR peaks results are consistent with proposed interactions between cellulose and $\mathrm{DMA} / \mathrm{LiCl}$ solvent system.
\end{abstract}

Keywords: Bacterial Cellulose; Electrospinning; Drug and Cell Delivery

\section{Introduction}

Cellulose is a semicrystalline polymer and its crystallinity depends on the originand on the isolation and processing methods. The complex structural hierarchy of cellulose, due to profuse hydrogen bonding, is manifested by the existence ofseveral polymorphs (crystalline forms). Native cellulose has a polymorph structure of cellulose I that exists in two crystalline forms: I $\alpha$ (in algae and bacteria) and $\mathrm{I} \beta$ (in higher plants) $[1,2]$. Although chemically identical to plant cellulose, the cellulose synthesized by bacterial has a fibrillar nanostructure which determines its physical and mechanical properties, characteristics which are necessary for modern medicine and biomedical research $[3,4]$. The structural features of microbial cellulose, its properties and compatibility of the biomaterial for regenerative medicine can be changed by modifying its culture medium [5-7] or surface modification by phyical [8] and chemical methods $[9,10]$ to obtain a biomaterial with less rejection with celular contact and blood contact cells interation. Moreover, the nanostructure and morphological similarities with collagen make $\mathrm{BC}$ attractive for cell immobilization and cell support. However, to obtain a biomaterial with less rejection and better celular contact and blood contact cells interation in human and animal medicine, homogeneous size porous is necessary. The chemical groups $(\mathrm{OH})$ found in the struc-

\footnotetext{
"Corresponding author.
}

ture of nanobiocellulose can serve as support for incorporation of drugs [11,12].

Cellulose chains have a strong tendency to aggregate to form highly ordered structures. The highly regular constitution of the cellulose molecule, the stiffness of the molecular chain and the extensive hydrogen bonding capacity favors molecular alignment and aggregation. In order to dissolve cellulose, one has to find a suitable solvent to break down the prevailing hydrogen bond network, i.e., the initial supramolecular structure of cellulose should be destroyed in order to obtain a homogeneous (one-phase) solution. The two-component DMA/LiCl solvent system is perhaps the most used for homogeneous cellulose modification [13]. The dissolution mechanism with $\mathrm{DMA} / \mathrm{LiCl}$ takes advantage of the strong intermolecular interaction between the cellulose and the strong dipole such as in the case of DMA carbonyl group. Homogeneous functionalization of $\mathrm{DMAc} / \mathrm{LiCl}$ provides a fairly inert and thermally stable solvent system for cellulose, which is still an important tool for a homogeneous conversion of the polysaccharide. These media which exemplarely small be treated here in some detail, dissolve even high molecular cellulose $(D P>1000)$ completely after preactivation at a $\mathrm{LiCl}$ concentration of 7\% $9 \%$ by weight. Advantages claimed for $\mathrm{DMA} / \mathrm{LiCl}$ solutions in homogeneous reactions of cellulose are a full availability of hydroxy groups, permitting a minimal chain degradation at a temperature below $100^{\circ} \mathrm{C}$, a high 
versatility with regard to the type of reaction intended and a favorable reagent yield due to rather small consumption for side reactions $[14,15]$.

In this work, bacterial cellulose mats was acetylated and after processing by electrospinning to produce artificial symmetric nanoporous that can be applied in catalysis, drug and cell delivery. An electrospinning system comprises a polymer solution, contained in a syringe with a connected. The polymer solution is usually provided a charge using a high voltage power source. In the process, a high voltage electric field is applied to the tip of the needle connected to the syringe containing the polymer solution. The charged polymer jet is directed to the grounded collector. As the jet travels in air, the solvent evaporates, resulting in formation of polymer fibers, which are collected as a nonwoven fiber mesh on the grounded collector $[16,17]$. The parameters that affect electrospinning can be classified into three categories: 1) solution parameters such as viscosity, conductivity/polarity, and surface tension; 2) process parameters such as applied electric voltage, tip-to-collector distance, diameter of the needle tip, feed rate, and the hydrostatic pressure applied to the polymer solution; and 3) ambient parameters such as temperature, air velocity, and humidity of the electrospinning chamber [18].

One of the advantages of the e-spinning process over the conventional film-casting technique is the highly porous nature of the electrospun (e-spun) fiber mats which exhibit much greater surface area that assumingly could allow drug molecules to diffuse out from the matrix much more conveniently [19], when these fibrous materials are used as carriers for delivery of drugs. E-spun CA fiber mats have been explored as affinity membranes [20] antimicrobial membranes [21], three-dimensional (3D) structures resembling the urinary bladder matrix (UBM) [22], and drug-delivery membranes [23].

\section{Materials and Methods}

\subsection{Materials}

The bacterial cellulose used as raw material here was Nanoskin ${ }^{\circledR}$ provided from Innovatec's (São Carlos SP, Brazil). Lithium chloride (BioXtra, $\geq 99.0 \%$-Sigma Aldrich); N,N dimethylacetamide (DMAc, puriss. p.a., $\geq 99.5 \%$-Sigma Aldrich); acetic anhydride ( $\geq 98.0 \%$-SynthBR); Methanol (anhydrous, >99\%-Synth-BR); Chloroform (anhydrous, $\geq 98 \%$-Synth-BR) were used as received.

\subsection{Methods}

\subsubsection{Cellulose Dissolution and Acetylation}

The dissolution and acetylation steps were based on Ass et al. with some modifications [24]. A mixture of bacterial cellulose and DMAc (0.051) was heated to $120^{\circ} \mathrm{C}$ and stirred for 2 hours, in a reflux condenser. After that, lithium chloride solution $\left(6 \mathrm{mmol} \cdot \mathrm{L}^{-1}\right)$ was ad- ded and the mixture was heated to $150^{\circ} \mathrm{C}$ with stirring for 2 hours. Then, acetic anhydride solution $\left(1 \mathrm{mmol} \cdot \mathrm{L}^{-1}\right)$ was added dropwise. The system was kept at $100^{\circ} \mathrm{C}$ for 1 hour and then cooled to room temperature. The product was precipitated with methanol and purified by Soxhlet extraction in methanol. After that, it was dried at $50^{\circ} \mathrm{C}$ in a vacuum oven.

\subsubsection{Solutions to Be Processed}

Solution was prepared at a concentration of $8 \% \mathrm{w} / \mathrm{w}$ of acetylated cellulose in chloroform. The solution was stirred on magnetic stirrer at room temperature for 3 hours. After this period the solution was processed by electrospinning using voltage of the $20 \mathrm{Kw}$ and $12 \mathrm{~cm}$ distance from the needle until collector. Nanofibers mats were collected in grounded metal collector.

\subsection{Characterization}

Scanning Electron Microscopy (SEM)—Scanning electronic microscopy images were performed on a PHILIPS XL30 FEG. The samples were covered with gold and silver paint for electrical contact and to perform the necessary images.

Transmission infrared spectroscopy (FTIR, Perkin Elmer Spectrum 1000) - Influences of $\mathrm{DMA} / \mathrm{LiCl}$ in bacterial cellulose was analyzed in the range between 250 and $4000 \mathrm{~cm}^{-1}$ and with resolution of $2 \mathrm{~cm}^{-1}$ with samples.

\section{Results and Discussion}

\subsection{SEM}

Bacterial cellulose mats were characterized by SEM. Figures 1(a) and (b) shows, as an example, SEM images of electrospun cellulose membrane samples are shown in Figure 1. Pores uniformly distributed throughout the fibers can be observed with a low size dispersion and average size around $20-100 \mathrm{~nm}$. As to electrospinning, previous studies have demonstrated that the deposition rate of fibers during electrospinning is in the order of several meters per second, the solution jet was elongated up in less than a second, and the elongation rate can reach up high velocity, which leads to a dramatic increase of the surface-area-to-volume ratio with in milliseconds. The orientation of pores along the longitudinal direction of the electrospun fibers is attributed to the rapid stretching effect during electrospinning $[25,26]$. In Figures 1 and 2, it can be observed different sizes porous formation with electrospinning and casting polymers mats. 


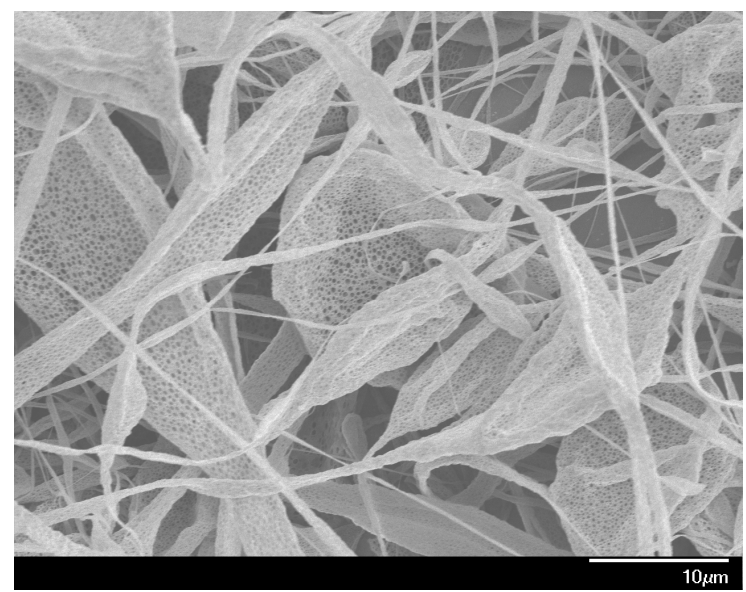

(a)

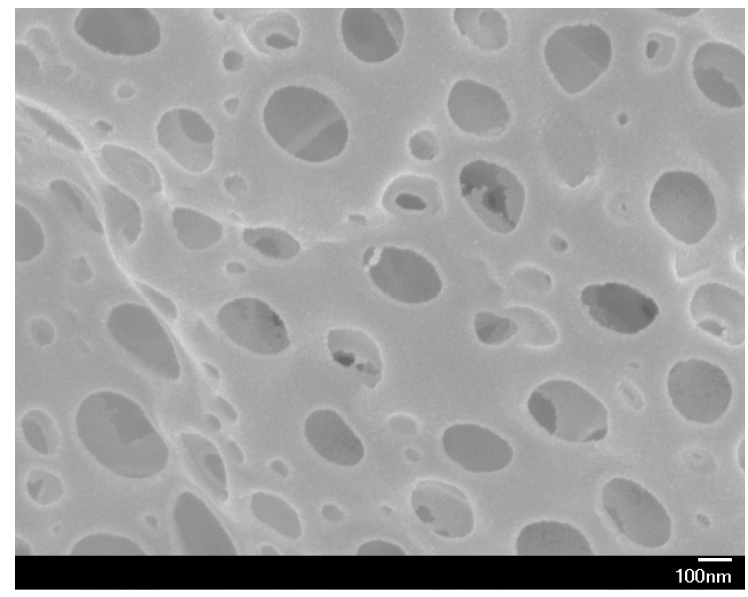

(b)

Figure 1. Micrographs of electrospun mats from BC-acetyl/ chloroform solution with ampliation: (a) 5000×; (b) 8500×.

Wendorff et al. [27] found that when spinning parameters and highly volatile solvents were chosen appropriately, porous electrospun fibers are obtained. So, with these changes is bacterial cellulose mats, modified bacterial cellulose were easily electrospun in chloroform/acetone solvents in comparison with $\mathrm{BC}$ unmodified, resulting in symmetric nanopore structure for drug and cell delivery.

\subsection{FTIR}

Influences of acetylation in bacterial cellulose electrospun mats was analyzed in the range between 250 and $4000 \mathrm{~cm}^{-1}$ and with resolution of $2 \mathrm{~cm}^{-1}$ with samples. The main features of the bacterial cellulose in infrared spectroscopy is: $3500 \mathrm{~cm}^{-1}$ : $\mathrm{OH}$ stretching, $2900 \mathrm{~cm}^{-1}$ : $\mathrm{CH}$ stretching of alkane and asymmetric $\mathrm{CH}_{2}$ stretching, $2700 \mathrm{~cm}^{-1}: \mathrm{CH}_{2}$ symmetric stretching, $1640 \mathrm{~cm}^{-1}: \mathrm{OH}$ deformation, $1400 \mathrm{~cm}^{-1}$ : $\mathrm{CH}_{2}$ deformation, $1370 \mathrm{~cm}^{-1}: \mathrm{CH}_{3}$ deformation, $1340 \mathrm{~cm}^{-1}$ : $\mathrm{OH}$ deformation and $1320-$ $1030 \mathrm{~cm}^{-1}$ : CO deformation [28]

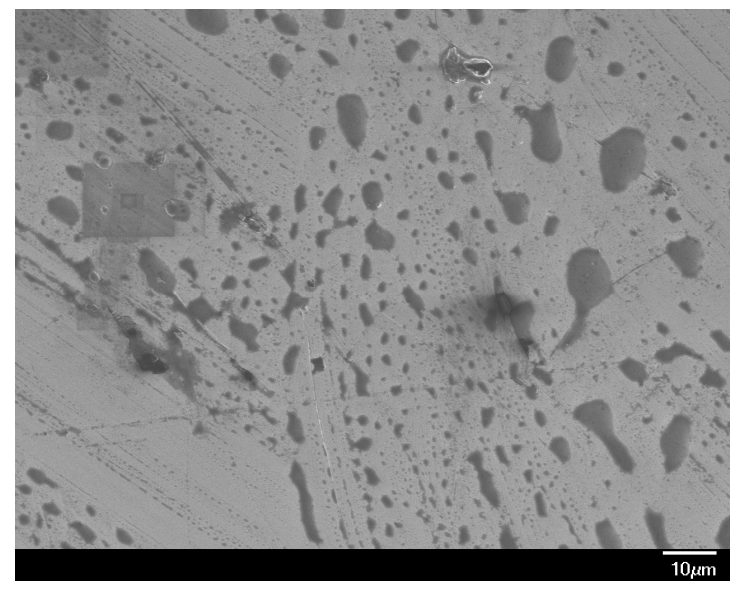

(a)

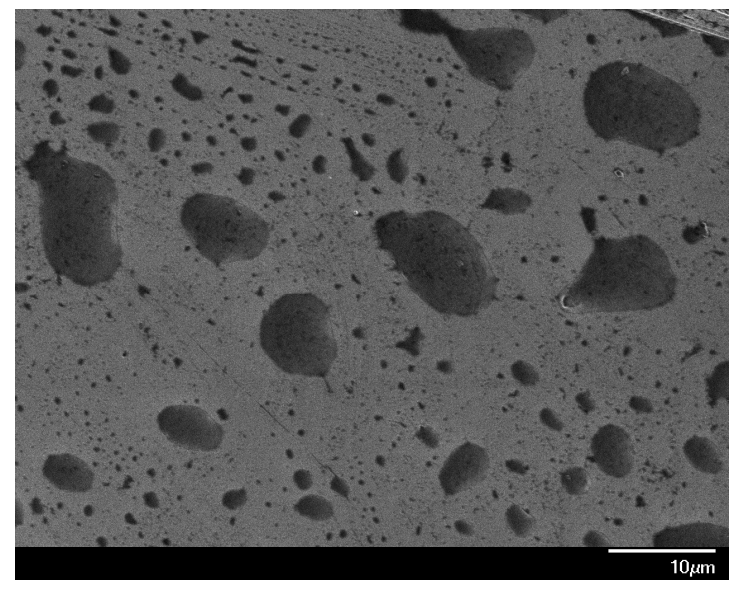

(b)

Figure 2. Micrographs of casting mats from a BC-acetyl/ chloroform solution with ampliation: (a) 5000×; (b) 8500×.

The mechanism of cellulose dissolution in DMA/LiCl family of solvents is accompanied by the strong intermolecular interaction between cellulose and a strong N-O dipole. The dissolution mechanism in $\mathrm{DMA} / \mathrm{LiCl}$ family of solvents takes advantage of the strong intermolecular interaction between the cellulose and the strong dipole such as in the case of DMA carbonyl group [29]. It can be observed that acetylation change mainly peaks at 3500 , 2900, $1750 \mathrm{~cm}^{-1}$ and region between $560-740 \mathrm{~cm}^{-1}$. FTIR spectra of the original bacterial membrane indicate a broad hydroxyl peak centering around 3500 - 3600 $\mathrm{cm}^{-1}$ and $\mathrm{CH}$ stretching of alkane at $2930 \mathrm{~cm}^{-1}$. It can be observed in Figures 3(a) and (b) that these groups of pure bacterial cellulose were changes by chemical treatment resulting in changes in FTIR peaks relative to the carbonyl peak at $1740 \mathrm{~cm}^{-1}$ (Figure 3(b)) and cloroalkanes peaks at $540-760 \mathrm{~cm}^{-1}$ (Figure 3(c)). It can also be concluded that because of evaporative cooling during electrospinning, the atmospheric water vapor condensed onto the fiber surface formed droplets leading to a porous surface fiber and this evaporation changes peaks intensity 
of peaks in electrospinning/casting films (Figures 3(a)(c)).

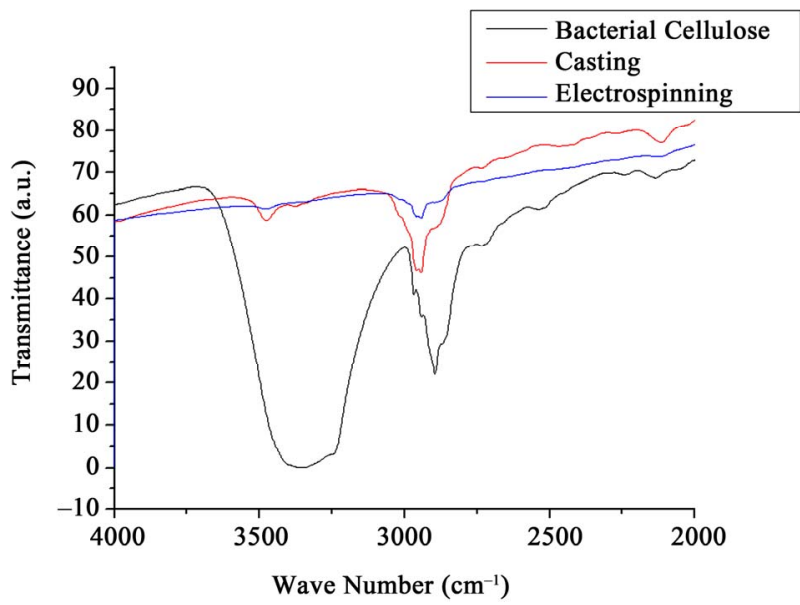

(a)

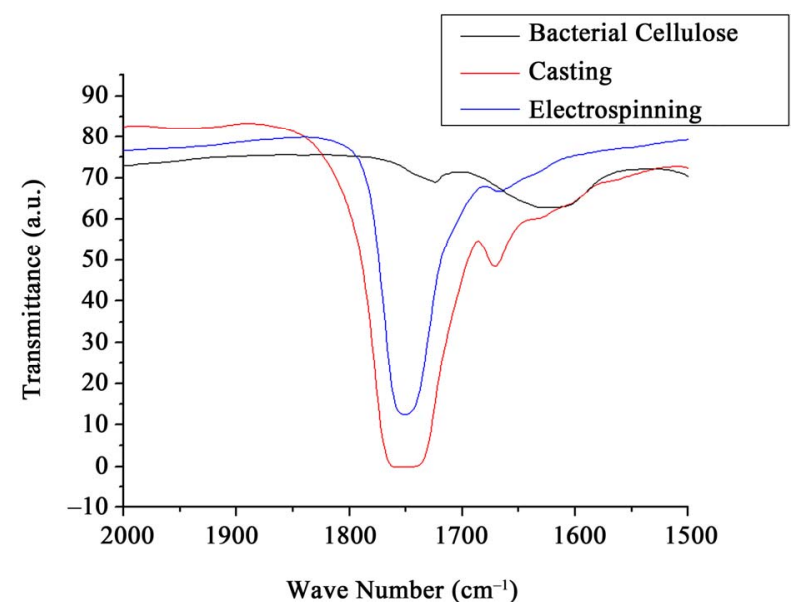

(b)

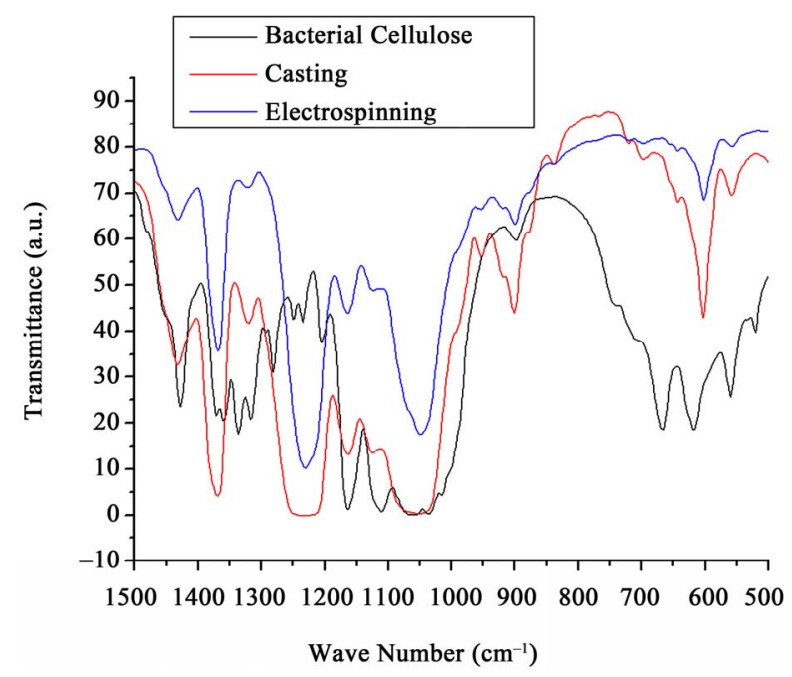

(c)

Figure 3. FTIR spectra of the samples BC, Chemical modified BC casting films and chemical modified BC electrospun mats.

\section{Conclusions}

It was reported a first bacterial cellulose electrospun by chemical modified groups. Electrospun bacterial cellulose mats presents more symmetric nanopore structure in bacterial cellulose than casting films mats observed by SEM images mainly because the orientation of pores along the longitudinal direction of the electrospun fibers is attributed to the rapid stretching effect during electrospinning. With $\mathrm{DMA} / \mathrm{LiCl}$ mechanism dissolution, modified bacterial cellulose were easily electrospun in chloroform/acetone solvents in comparison with $\mathrm{BC}$ unmodified because spinning parameters and highly volatile solvents were chosen appropriately after BC modification. FTIR peaks results are consistent with proposed interactions between cellulose and $\mathrm{DMA} / \mathrm{LiCl}$ solvent system.

These results confirm that the $\mathrm{BC}$ is ideal scaffold requires with porous structure which can provide maximum integration with cells and body fluids, plus have a nanostructure surface which facilitates the adhesion of cells.

\section{Acknowledgements}

Innovatec's-Biotechnology Research and Development, UFABC, CAPES.

\section{REFERENCES}

[1] P. Gatenholm and D. Klemm, "Bacterial Nanocellulose as a Renewable Material for Biomedical Applications," MRS Bulletin, Vol. 35, No. 3, 2010, pp. 208-213.

[2] W. K. Czaja, D. J. Young, M. Kawecki and R. M. Brown Jr., "The Future Prospects of Microbial Cellulose in Biomedical Applications," Biomacromolecules, Vol. 8, No. 1, 2007, pp. 1-12. doi:10.1021/bm060620d

[3] M. Shoda and Y. Sugano, "Recent Advances in Bacterial Cellulose Production," Biotechnology Bioprocess Engineering, Vol. 10, No. 1, 2005, pp. 1-8. doi:10.1007/BF02931175

[4] P. A. Richmond, "Biosynthesis and Biodegradation of Cellulose, Occurrence and Functions of Native Cellulose," C. H. Haigler and P. J. Weimer, Eds., Marcel Dekker, New York, 1991, p. 23.

[5] C. H. Haigler, A. R. White and R. M. Brown, “Alteration of in Vivo Cellulose Ribbon Assembly by Carboxymethylcellulose and Other Cellulose Derivatives," The Journal of Cell Biology, Vol. 94, No. 1, 1982, pp. 64-69. doi:10.1083/jcb.94.1.64

[6] E.-L. Hult, S. Yamanaka and M. Ishihara, "Aggregation of Ribbons in Bacterial Cellulose Induced by High Pressure Incubation," Carbohydrate Polymer, Vol. 53, No. 1, 2003, pp. 9-14. doi:10.1016/S0144-8617(02)00297-7

[7] K. Watanabe, M. Tabuchi and M. Yasushi, "Features and Properties of Bacterial Cellulose Produced in Agitated Culture," Cellulose, Vol. 5, No. 3, 1998, pp. 187-200. doi:10.1023/A:1009272904582 
[8] J. Andersson, J. Sanchez, K. N. Ekdahi, G. Elgue, B. Nilsson and R. Larsson, "Optimal Heparin Surface Concentration and Antithrombin Binding Capacity as Evaluated with Human Non-Anticoagulated Blood in Vitro," Journal of Biomedical Materials Research A, Vol. 67, No. 2, 2003, pp. 458-466. doi:10.1002/jbm.a.10104

[9] F. K. Andrade, R. Costa, L. Domingues, R. Soares and M. Gama, "Improving Bacterial Cellulose for Blood Vessel Replacement: Functionalization with a Chimeric Protein Containing a Cellulose-Binding Module and an Adhesion Peptide," Acta Biomaterialia, Vol. 6, No. 10, 2010, pp. 4034-4041. doi:10.1016/j.actbio.2010.04.023

[10] F. K. Andrade, S. M. Moreira, L. Domingues and F. M. Gama, "Improving the Affinity of Fibroblasts for Bacterial Cellulose Using Carbohydrate-Binding Modules Fused to RGD," Journal of Biomedical Materials Research A, Vol. 92, No. 1, 2009, pp. 9-17.

[11] K. Rahn, M. Diamantoglou, D. Klemm and H. Berghmans, "Homogeneous Synthesis of Cellulose p-Toluenesulfonates in N,N-Dimethylacetamide/LiCl Solvent System," Makromolecular Chemistry, Vol. 238, No. 1, 1996, pp. 143-163. doi:10.1002/apmc.1996.052380113

[12] S. Tungprapa, I. Jangchud and P. Supaphol, "Release Characteristics of Four Model Drugs from Drug-Loaded Electrospun Cellulose Acetate Fiber Mats," Polymer, Vol. 48, No. 17, 2007, pp. 5030-5041. doi:10.1016/j.polymer.2007.06.061

[13] T. Heinze, R. Dicke, A. Koschella, A. H. Kull, E.-A. Klohr and W. Koch, "Effective Preparation of Cellulose Derivatives in a New Simple Cellulose Solvent," Macromolecular Chemistry Physics, Vol. 201, No. 6, 2000, pp. 627-631.

doi:10.1002/(SICI)1521-3935(20000301)201:6<627::AID -MACP627>3.0.CO;2-Y

[14] C. L. McCormick and D. K. Lichatowich, "Homogeneous Solution Reactions of Cellulose, Chitin, and Other Polysaccharides to Produce Controlled-Activity Pesticide Systems," Journal Polymer Science, Part B: Polymer Letters, Vol. 17, No. 8, 1979, pp. 479-484.

[15] C. L. McCormick and T. R. Dawsey, "Preparation of Cellulose Derivatives via Ring-Opening Reactions with $\mathrm{Cy}-$ clic Reagents in Lithium Chloride/N,N-Dimethylacetamide," Macromolecules, Vol. 23, No. 15, 1990, pp. 3606-3610. doi:10.1021/ma00217a011

[16] D. H. Reneker and A. L. Yarin, "Electrospinning Jets and Polymer Nanofibers," Polymer, Vol. 49, No. 10, 2008, pp. 2387-2425. doi:10.1016/j.polymer.2008.02.002

[17] S. Agarwal, J. H. Wendorff and A. Greiner, "Use of Electrospinning Technique for Biomedical Applications," Polymer, Vol. 49, No. 26, 2008, pp. 5603-5621. doi:10.1016/j.polymer.2008.09.014

[18] C. J. Thompson, G. G. Chase, A. L. Yarin and D. H. Reneker, "Effects of Parameters on Nanofiber Diameter Determined from Electrospinning Model," Polymer, Vol. 48, No. 23, 2007, pp. 6913-6922. doi:10.1016/j.polymer.2007.09.017
[19] E. R. Kenawy, G. L. Bowlin, K. Mansfield, J. Layman, D. G. Simpson, E. H. Sanders and G. E. Wnek, "Release of Tetracycline Hydrochloride from Electrospun Poly(EthyleneCo-Vinylacetate), Poly(Lactic Acid), and a Blend," Journal of Controlled Release, Vol. 81, No. 1-2, 2002, pp. 5764. doi:10.1016/S0168-3659(02)00041-X

[20] X. H. Zong, K.Kim, D. F. Fang, S. F. Ran, B. S. Hsiao and B. Chu, "Structure and Process Relationship of Electrospun Bioabsorbable Nanofiber Membranes," Polymer, Vol. 43, No. 16, 2002, pp. 4403-4412. doi:10.1016/S0032-3861(02)00275-6

[21] Z. Ma, M. Kotaki and S. Ramakrishna, "Electrospun Cellulose Nanofiber as Affinity Membrane," Journal of Membrane Science, Vol. 265, No. 1-2, 2005, pp. 115-123. doi:10.1016/j.memsci.2005.04.044

[22] W. K. Son, J. H. Youk and W. H. Park, "Antimicrobial Cellulose Acetate Nanofibers Containing Silver Nanoparticles," Carbohydrate Polymers, Vol. 65, No. 4, 2006, pp. 430-434. doi:10.1016/j.carbpol.2006.01.037

[23] P. Taepaiboon, U. Rungsardthong and P. Supaphol, "Vitamin-Loaded Electrospun Cellulose Acetate Nanofiber Mats as Transdermal and Dermal Therapeutic Agents of Vitamin A Acid and Vitamin E," European Journal of Pharmaceutics and Biopharmaceutics, Vol. 67, No. 2, 2007, pp. 387-397. doi:10.1016/j.ejpb.2007.03.018

[24] B. A. Ass, G. T. Ciacco and E. Frollini, "Cellulose Acetates from Linters and Sisal: Correlation between Synthesis Conditions in DMAc/LiCl and Product Properties," Bioresource Technology, Vol. 97, No. 14, 2006, pp. 16961702. doi:10.1016/i.biortech.2005.10.009

[25] M. Bognitzki, T. Frese, M. Steinhart, A. Greiner and J. H. Wendorff, "Preparation of Fibers with Nanoscaled Morphologies: Electrospinning of Polymer Blends," Polymer Engineering Science, Vol. 41, No. 6, 2001, pp. 982-989. doi:10.1002/pen.10799

[26] M. Wang, J. H. Yu, D. L. Kaplan and G. C. P. Rutledge, "Production of Submicron Diameter Silk Fibers under Benign Processing Conditions by Two-Fluid Electrospinning," Macromolecules, Vol. 39, No. 3, 2006, pp. 11021107. doi:10.1021/ma0517749

[27] M. Bognitzki, W. Czado, T. Frese, A. Schaper, M. Hellwig, M. Steinhart, A. Greiner and J. H. Wendorff, "Nanostructured Fibers via Electrospinning," Advanced Materials, Vol. 13, No. 1, 2001, pp. 70-72.

doi:10.1002/1521-4095(200101)13:1<70::AID-ADMA70 $\geq 3.0 . \mathrm{CO} ; 2-\mathrm{H}$

[28] M. Szymańska-Chargot, J. Cybulska and A. Zdunek, "Sensing the Structural Differences in Cellulose from Apple and Bacterial Cell Wall Materials by Raman and FT-IR Spectroscopy," Sensors, Vol. 11, No. 6, 2011, pp. 55435560 .

[29] D. Klemm, B. Philipp, T. Heinze, U. Heinze and W. Wagenknecht, "Comprehensive Cellulose Chemistry: Fundamentals and Analytical Methods," Wiley-VCH, Weinheim, 1998, p. 377. doi:10.1002/3527601937.indsub 